\title{
7039423
}

NASA TECHNICAL MEMORANDUM

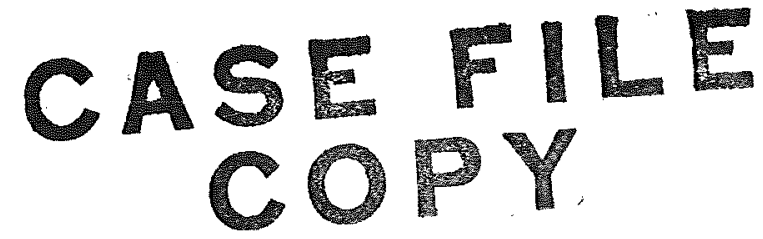

\section{OPTICAL ANALYSIS OF BALL BEARING STARVATION}

by L. D. Wedeven, D. Evans, and A. Cameron

Lewis Research Center

Cleveland, Ohio

TECHNICAL PAPER proposed for presentation at Lubrication Conference sponsored by the American Society of Mechanical Engineers and the American Society of Lubrication Engineers Cincinnati, Ohio, October 12-15, 1970 


\author{
OPTICAL ANALYSIS OF BAIL BEARING STARVATION \\ by I. D. Wedeven, D. Evans ${ }^{*}$ and A. Cameron \\ National Aeronautics and Space Administration \\ Lewis Research Center \\ Cleveland, Ohio
}

\begin{abstract}
Elastohydrodynamic oil film measurements for rolling point contact under starvation conditions are obtained using optical interfer ometry. The experimental measurements present a reasonably clear picture of the starvation phenomenon and are shown to agree with theoretical predictions. Starvation inhibits the generation of pressure and, therefore, reduces film thickness. It also causes the overall pressure, stress and elastic deformation to become more Hertzian.
\end{abstract}

Additional experiments using interferometry illustrate: The cavitation pattern, lubricant entrapment, grease lubrication, ball spin, and edge effects in line contact.

\title{
INTRODUCTION
}

The thickness of the hydrodynamic film between bearing surfaces is a very important consideration, particularly for elastohydrodynamic (EHD) conditions where film thickness and surface irregularities are often of the same order of magnitude. The present state of BHD shows that the development of an EHD film is now quite well understood, and that the thickness of such films can be predicted theoretically with commendable accuracy. Presently, some investigations are concerned with isolated aspects of EHD and the explanations of discrepancies between theory and experiment. Considerable emphasis is being placed on the application of EHD principles to establish the most favorable operating conditions in machine elements.

Many applications, however, do not operate under the ideal conditions which are normally assumed or provided in most theoretical and experimental investigations. An important practical consideration which is often omitted is the supply and distribution of lubricant in England.

*Center for Computation and Automation, Imperial College, London,

\footnotetext{
tIubrication Laboratory, Department of Mechanical Engineering,
} Imperial College, London, England. 
the vicinity of the contact region. Lubricant starvation, which may often exist but not always be recognized, can have an overriding effect on film thickness and other EHD aspects.

An important aspect inherent in the $\mathrm{HH}$ problem which was brought out in the Grubin theory [1] is that film thickness is primarily developed in the inlet region, just in advance of the flat Hertzian region. The experimental work of crook [2] and the thermal solutions of Cheng and Sternlicht [3] and Dowson and Whitaker [4] provide further evidence of the fact that film thickness is governed by the conditions in the inlet region. Therefore, the conditions of speed, viscosity, and geometry, as far as film thickness is concerned, must be those relevant to the inlet region. These are the controlling variables in the film thickness equations.

A condition of the inlet region which is not represented in the film thickness equations is that of the supply of lubricant. Hydrodynamic considerations require the gap between the surfaces to be adequately filled to facilitate the important pressure buildup. If the inlet region is adequately filled with lubricant, the inlet pressure buildup will develop a film thickness which is insensitive to the further increases in lubricant supply. This condition of lubrication is defined as "flooded". If the inlet region is inadequately filled, the inlet pressure buildup will be delayed, and a film thkckness which is dependent upon the available lubricant supply will result. The condition of lubrication is then defined as "starved". This starved condition of lubrication, which has received very little theoretical and experimental consideration, forms most of the work presented here. The experimental and theoretical work is limited to EHD point contact conditions; however, the fundamental features have more general application.

\section{NOMENCLATURE}

$\begin{array}{ll}\text { Hertzian radius } \\ \AA & \text { Angstrom unit } \AA=10^{-8} \mathrm{~cm}\end{array}$

$B$ dimensionless term in Hertzian equation $=\frac{3 w}{2 \pi a E^{\top} h_{0}}$

$\mathbb{E}_{12} \mathbb{E}_{2}$ modulus of elasticity of bearing materials

$\mathrm{E}^{\prime}$ reduced elastic modulus; $\frac{1}{\mathrm{E}^{\prime}}=\frac{1}{2}\left[\frac{1-\sigma_{1}^{2}}{\mathrm{E}_{1}}+\frac{1-\sigma_{2}^{2}}{\mathrm{E}_{2}}\right]$

h film thickness 
$h_{b} \quad$ film thickness at. Iubricant boundary

$h_{H} \quad H e r t z i a n$ deformation for dry contact

$\mathrm{h}_{\mathrm{m}} \quad$ minimum film thickness

$h_{0} \quad$ central film thkckness

$\left(h_{0}\right)_{f}$ central film thickness under flooded conditions

$h^{*}$ dimensionless film thickness $=h / h o$

$m$ transformed distance, $m=\log _{e} r^{*}$

p pressure

$p_{\max } \quad$ maximum Hertzian pressure

q

$q^{*}$

$q_{\max }^{*}$

reduced pressure $=\frac{1}{\alpha}\left(1-e^{-\alpha p}\right)$

dimensionless reduced pressure $=\frac{h_{0}^{2} q}{12 \mu_{0} u a}$

maximum dimensionless reduced pressure $=\frac{h_{0}^{2}}{12 \mu_{0} \text { uad }}$

$r$

$r^{*}$

radius from center of Hertzian region

dimensionless radius $=r / a$

$R \quad$ reduced radius of contact, $\frac{1}{R}=\frac{1}{R_{1}}+\frac{l}{R_{2}}$

$\mathrm{R}_{1}, \mathrm{R}_{2} \quad$ radius of contacting bodies

$\mathrm{s} \quad$ inlet distance, $\mathrm{S}=\left(\mathrm{x}_{\mathrm{b}}-\mathrm{a}\right)$

$S_{f} \quad$ inlet distance to obtain a flooded condition

u

combined surface velocity $=\frac{1}{2}\left(u_{1}^{\prime}+u_{2}\right)$

$u_{1}, u_{2}$ velocity of bearing surfaces

w load on bearing contact

$\mathrm{x}, \mathrm{y}, \mathrm{z}$ coordinates

$x_{b}$

distance from the inlet lubricant boundary to the center of the Hertzian region

$\alpha \quad$ pressure viscosity coefficient

$\theta \quad$ angulare dimension from axis of symmetry

$\mu \quad$ local viscosity of lubricant

$\mu_{0} \quad$ ambient viscosity of lubricant

$\sigma_{1}, \sigma_{2}$ Poisson's ratio of bearing materials

$\phi$

transformed angular dimension, $\pi^{\phi}=2 \theta$ 


\section{THEORY}

\section{Reynolds Equation}

Reynolds equation is

$$
\frac{\partial}{\partial x}\left(\frac{h^{3}}{\mu} \frac{\partial p}{\partial x}\right)+\frac{\partial}{\partial y}\left(\frac{h^{3}}{\mu} \frac{\partial p}{\partial y}\right)=12 u \frac{\partial h}{\partial x}
$$

Viscosity is assumed to vary with pressure according to

$$
\mu=\mu_{0} e^{\alpha p}
$$

A reduced pressure, $q$, is defined as

$$
q=\frac{1}{\alpha}\left(1-e^{-\alpha p}\right)
$$

Reynolds equation then becomes

$$
\frac{\partial}{\partial x}\left(h^{3} \frac{\partial q}{\partial x}\right)+\frac{\partial}{\partial y}\left(h^{3} \frac{\partial q}{\partial y}\right)=12 u \mu_{0} \frac{\partial h}{\partial x}
$$

Grubin [1] applied this to line contact (where $\partial \alpha / \partial y=0$ ) by assuming (i) the shape outside the contact was Hertzian and (ii) that $q \approx 1 / \alpha$ everywhere inside the contact. The validity of this has previously been discussed (e.g., ref. 5). The Grubin analysis has been extended to point contacts by Cameran and Gohar [6], Archard and Cowking [7], and more recently by cheng [8].

The contact geometry is shown in Fig. 1 . The film thickness $h$ at any point is the sum of the central film thickness $h_{0}$ and the Hertzian deformation for dry contact [5]. Thus

$$
h=h_{0}+\frac{3 w}{2 \pi a E^{1}}\left[\left(\frac{r^{2}}{a^{2}}-1\right)^{1 / 2}-\left(2-\frac{r^{2}}{a^{2}}\right) \cos ^{-1} \frac{a}{r}\right]
$$


Define

$$
B=\frac{3 w}{2 \pi a E^{\prime} h_{0}}
$$

so that

$$
h=h_{0}\left\{1+B\left[\left(\frac{r^{2}}{a^{2}}-1\right)^{1 / 2}-\left(2-\frac{r^{2}}{a^{2}}\right) \cos ^{-1} \frac{a}{r}\right]\right\}
$$

To reduce the parameters of the problem the following terms are defined:

$$
r^{*}=\frac{r}{a}, \quad h^{*}=\frac{h}{h_{0}}, \quad q^{*}=\frac{q h_{0}^{2}}{12 \mu_{0} \text { ua }}
$$

Also, as the pressure falls rapidly with distance a new distance $m$ is chosen $m=\log _{e} r^{*}$. Also, an angle $\phi$, chosen so it ranges from +1 to- 1 is defined as $\pi^{\phi}=2 \theta$ where $\theta$ is the angular displacement from the line of fluid motion on the axis of symmetry.

Applying these transforms Reynolds equation takes the form

$$
\frac{\partial^{2} q^{*}}{\partial m^{2}}+\frac{4}{\pi^{2}} \frac{\partial^{2} q^{2}}{\partial \phi^{2}}+\frac{3}{h} \frac{\partial h}{\partial m} \frac{\partial q^{*}}{\partial m}=e^{m} \cos \frac{\pi^{\phi}}{2} \cdot \frac{1}{h^{3}} \frac{\partial h}{\partial m}
$$

\section{Boundary Conditions}

1. Along, $A B$ (Fig. 1)

Due to symmetry along $A B, \frac{\partial q^{*}}{\partial \phi}=0$

2. Along $B C$

$\mathrm{q}^{*}=0$ along $\mathrm{BC}$ at some value of $r^{*}$. This is the inlet boundary condition which is located at decreasing values of $r *$ to obtain starvation conditions.

3. Along CD ( ide leakage)

$\mathrm{q}^{*}=\mathrm{q}^{*} / \mathrm{h}^{2}$ along $\mathrm{CD}$. The power of $1 / \mathrm{h}$ was initially set to 2 as in max [6]; but, for low values of $B$ in the neighborhood of the Hertz radius minima would occur inside the boundary $\phi=1$ instead of on the boundary. A more compatible boundary condition could 
be obtained by increasing the power of $1 / h$. However, the nature of the side leakage had no effect on the values along the axis of symmetry.

4. Along DA (Hertz radius)

The Grubin solution shows $q \rightarrow \frac{1}{\alpha}$ and $\partial q / \partial m \rightarrow 0$ at the Hertzian radius. Therefore, $q^{*}=q^{*}$ a. ${ }^{*}$ ng $D A$; however $\partial q^{*} / \partial m=0$ was only held at point A. The $e^{*}$ values along the axis of symmetry were used to estimate the derivative of $q^{*}$ at the Hertz radius $(m=0)$. Sufficiently good starting values for $q^{*}$ at $m=0$ resulted in derivatives which were linearly dependent on the $q_{\max }^{*}$ value and thus linear interpolation of a few values enabled $q_{\max }^{*}$ with $\partial q^{*} / \partial \mathrm{m}=0$ to be attained.

Finite - Difference Approximation

The $(m, \phi)$ plane is covered by a moderately fine mesh of up to 50 equidistant steps in the $m$ direction and up to 36 in the $\phi$ direction totaling 1800 points. 2 and 3 point finite differences were used as approximations to the partial derivatives yielding a 5-point difference equation for each mesh point. Application of such a formula to all mesh points results in a matrix equation $A x=b$ where $x$ is the column vector of values at each mesh point, $b$ is a column vector of constants and $A$ is a (1800 $\times 1800)$ matrix.

\section{Inversion of a Large Matrix}

Such a matrix would be impossible to invert (or even store) on present-day computers. The nature of $A$ is such that it may be partitioned into submatrices $-\mathrm{w}$ ith each row of submatrices consisting of three matrices (maximum $36 \times 36$ ), two of which are diagonal matrices.

Inversion of the original matrix is achieved by Gaussian Elimination Process with the submatrices and their inverses replacing the conventional elements and reciprocals.

\section{Starting Values}

A "reasonable" value for $q^{*}$ at the Hertzian radius $(m=0)$ for a given value of $B$ is used and the m-interval (initially set so that the boundary is well outside the pressure field) is reduced thus bringing in the boundary until the vector of q-values beings to change. This then establishes the boundary for the particular flooded case and the minimum interval is achieved. Next the number of intervals, which is initially 36, is reduced until the "picture" changes. The speed of the program is mainly determined by the size of this number. 
Results for Flooded Condition

The values of $q^{*}$ were determined for a fairly extensive range of $B$ values wlth $\log _{10} B$ ranging from -3 to +3 . A plot of $\log _{10} q_{\max }^{*}$ against $\log _{10} \mathrm{~B}$ gave a good straight line in the range $\log _{10} B=-0.2$ to 1.0 giving

$$
q_{\max }^{*}=0.093 \mathrm{~B}^{-0.6}
$$

Remembering that at the Hertzian radius $q \rightarrow \frac{1}{\alpha}$ and

$$
q_{\max }^{*} \rightarrow \frac{h_{0}^{2}}{12 \mu_{0} \text { ua } \alpha}
$$

the following film thickness formula for a flooded condition is obtained:

$$
\frac{h_{0}}{R}=1.73\left(\frac{\alpha_{0} u}{R}\right)^{5 / 7}\left(\frac{w}{E^{\prime} R^{2}}\right)^{-1 / 21}
$$

\section{Results for Starved Condition}

The results for a starved condition are represented in Fig. (2). Here $q^{*}$ is plotted against $n$ (where $r^{*}=1+2^{n-5}$ ) for constant values of $q * B^{2}$. $q * B^{2}$ can be determined from the operating conditions as shown in [9].

$$
q * B^{2}=\frac{1}{8 \pi^{2}}\left(\frac{\alpha \mu_{o} u}{R}\right)^{-1}\left(\frac{w}{E^{\prime} R^{2}}\right)
$$

For a given inlet condition $r^{*}, q^{*}$ can be determined from Fig. (2) and $h_{0}$ can be calculated from equation (10). 
EXPERTMENTAI PRELIMINARIES

Apparatus

A schematic diagram of the apparatus is shown in Fig. 3. The apparatus provides a system whereby the EHD film thickness in a ball thrust bearing can be measured using optical interferometry. The experimental bearing is shown in Fig. 4. It consists of two flat races separated by three 1 -inch diameter steel balls. The lower race is made of steel and is supported by an air thrust bearing which is driven by an electric motor. The upper race is an optical crown glass disk 6 inches in diameter and $1 / 2$-inch thick. Its lower surface is coated with 2 thin $(\sim 170 \AA)$ chromium layer of 15 percent reflectivity, and its upper surface has an antireflection coating. Load is applied to the upper race with a lever arm, and the interference fringes are observed with a microscope having a magnification of $\mathrm{X} 50$.

The bearing was operated in a counterrotation mode for most of the experiments by holding the cage stationary (Fig. 4). This causes the test ball, which can be adjusted radially in a laminated phenolic cage, to rotate about a single axis fixed in space. Both bottom and top race speeds were measured with a magnetic transducex. Slip measurements between races were always less than 2 percent for all experimental conditions.

The bearing was also operated by holding the top race stationary, The balls then have curvilinear as well as rotational motion. The interference fringes of the test ball are then observed stroboscopically by synchronizing the light source with the cage by means of a lamp and phototransistor as shown in Fig. 3 .

The microscope is illuminated with a xenon discharge tube which emits white light at a color temperature of $6000^{\circ} \mathrm{K}$. The tube can be discharged at a high repetition rate for continuous observations, and it can be discharged singly for high-speed photography.

The requirements for good fringe "visibility" and how they can be used to design an interferometric system which is compatible with the experimental measurements is discussed in [9]. A duochromatic system which is composed of green and red wavebands, obtained with a Wratten $77 \mathrm{~A}$ filter, provides fringes of good "visibility" over a satisfactory film thickness range of 80 microinches. The fringes are closely spaced and form a definite color sequence which can be used to determine fringe order. The calibration of this system is given in [9] and [10].

To obtain the absolute thickness corresponding to each fringe the calibrated fringes (obtained in air) must be divided by the refractive 
index of the medium. A maximum experimental pressure of 87000 psi increases the refractive index of a typical oil by about 8 percent from its atmospheric value. The Lorenz-Lorentz relation [11] was used to determine the change of refractive index with density, and the Hartung empirical formula for hydrocarbons [12] was used to determine the change in density with pressure.

Film Thickness Measurements (Flooded)

Experimental film thickness measurements using a lubricant (LUB D) that is well documented [13] are plotted in Fig: 5 as a function of four theoretical film thickness formulas. There is a very good agreement between theory and experiment for the present formula (Eq. II) and that of Cheng [8]. These solutions were based on Grubin assumptions have enabled a reasonably accurate film thickness formula for point contacts to be developed in the same manner as they did for line contact in the $1950^{\circ} \mathrm{s}$ when a full solution had not yet been achieved.

Figure 6 is a plot of the measured film shape obtained from a high-speed photomicrograph [9]. The measurements were corrected for refractive index change by using an estimated pressure profile. The film shape in the transverse direction shows that the minimum film thickness $h_{m}$ at the lateral constrictions ( $h_{m}=8.5$ microinch) is much less than the central film thickness ( $h \stackrel{m}{=} 18.3$ microinch). The ability to predict the minimum film thickness is of practical importance. The central film thickness $\left(h_{0}\right)$ and the minimum film thickness $\left(h_{m}\right)$ as measured from random photomicrographs taken over a range of loads between $1.92 \mathrm{lbf}$ and $12 \mathrm{lbf}$ are plotted in Fig. 7. The data for a materials combination of sapphire/tungsten carbide given by Gohar [14] are also included. The plot shows a certain degree of scatter because $h_{m}$ is more sensitive to load than $h_{0}$. However, to a first approximation

$$
h_{m} \approx \frac{h_{0}-4.5 \text { microinches }}{1.4}
$$

An interesting feature of the results is that the load parameter $\left(\frac{w}{E^{\prime} R^{2}}\right)$
for the sapphire/tungsten carbide is nearly the same as the lowest load parameter for the glass/steel data. These two cases show very good correlation even though the reduced elastic modulus of the former $\left(66.6 \times 10^{6} \mathrm{psi}\right)$ is four times the latter, and the maximum Hertzian pressure of the former ( $405000 \mathrm{psi})$ is over eight times the latter. 


\section{STARVATION EXPERIMENTS}

\section{Inlet Lubricant Boundary and Film Shape}

The starvation experiments were conducted with the bearing operating in the counterrotation mode. Before each test the bearing components were cleaned with a solvent (either benzene or acetone). Lubricant was applied to the ball and raceway surfaces during the reassembly of the bearing. Under static conditions surface tension causes the lubricant to form a circular boundary or meniscus around the contact region. A side view of the meniscus can be seen in Fig. 4 .

Under dynamic conditions the quantity and distribution of lubricant in the inlet region is reflected in the shane and location of the lubricant boundary in the inlet region. Figs. 8(a) and (b) show clearly defined areas where the gap between the bearing surfaces is completely filled with lubricant. Since the medium is continuous in these areas they form very uniform interference fringes. Outside these areas the medium is a composite of air and oil, and the fringes which form between the ball and glass race are shifted to locations of greater thickness because the refractive index of air is less than oil. This is clearly seen in the inlet region of Fig. 8(b). The degree of fringe shift depends on the relative amounts of air and oil at each location. In this way the rippled fringes in the inlet region show quantitatively the distribution of lubricant on the bearing surfaces. A fringe which is shifted closer to the Hertzian region indicates a greater percent of oil.

The rippled fringes in the inlet region also show that the lubricant is distributed over the bearing surfaces in the form of small ribs which are generally oriented in the direction of motion. These ribs are developed in the outlet region where the lubricant film ruptures into striations of air and oil. These ribs, though somewhat flattened out, can also be seen in the inlet region. In this way the amount and distribution of lubricant in the outlet region influences the inlet region.

Excess Iubricant is frequently found on the sides of the track as shown in Fig. 8(b). These areas act as reservoirs from which lubricant can flow into the inlet region by the action of surface tension. The rate of flow is probably a function of surface tension, viscosity, gap thickness, and the shape of the lubricant boundary; and the amount of lubricant which is recaptured in the inlet region by surface tension will certainly depend on the time available, i.e., the speed of the bearing surfaces. The amount and distribution of lubricant which fills the gap at any given time is clearly determined by the inlet lubricant boundary. 
The EHD films shown in Fig. 8 are clearly affected by a starved inlet region; and the film shape, which can be obtained by reading the fringes as lines of constant thickness, is strongly dependent upon the shape of the inlet lubricant boundary. The EHD film of Fig. $8(\mathrm{c})$ is very severely starved and consists of a series of channels. These channels are caused by the ribs of lubricant which can be seen in the inlet region.

These results not only show that the film thickness is primarily determined in the inlet region, but also that the local film thickness at each point within the Hertzian region is primarily a function of the micro inlet conditions immediately upstream of that point.

Test Conditions and Procedure

The purpose of the starvation expeximents was to determine the effect of the inlet boundary on the central film thickness for a range of operating conditions. For constant speed, load, and lubricant properties the required information is the central film thickness $h_{0}$ and the boundary distance $x_{\text {p }}$ measured from the center of the Hertzian region to the inlet boundary immediately upstream (see Fig. 9). These measurements were taken from high-speed photomicrographs.

Starvation was achieved by gradually reducing the quantity of lubricant within the bearing system. The chosen operating conditions consisted of three loads on the test ball (1.92, 6, and $121 \mathrm{bf}$ ) and four initial (i.e., flooded) film thicknesses which correspond to the first four red fringes of the duochromatic system. All combinations of the chosen operating conditions were tested, thus giving twelve individual test runs. The three test loads give a maximum Hertzian pressure ranging from 47400 to 87000 psi, and the four initial film thicknesses range from 8 to 30 microinches. To maintain a convenient operating speed, on the order of $10 \mathrm{in} . / \mathrm{sec}$, these film thicknesses were obtained by varying the test lubricant as well as the bearing speed. Five test lubricants were used. Their properties are shown in Table 1. The lubricants designated SAE 10, SAE 30, and SAE 40 are paraffinic mineral oils, while TN 631 is a medium viscosity index naphthenic mineral oil. IUB $D$ is a high viscosity, low viscosity index mineral oil which was previously used by Dyson et al. [15] and Foord et al. [16]. It was used here as a reference fluid from which the pressure-viscosity coefficients of the other test lubricants were obtained. The apparatus itself was used to obtain the pressureviscosity coefficients in the manner described by Foord et al. [16]. 
Starvation Results

Figure 10 shows a sample of photomicrographs taken from a test run. The test load is 1.92 Ibf, and the initial film thickness corresponds to the fourth red fringe ( $h=30$ microinches). In Fig. $10(a)$ the boundary distance is sufficiently removed from the center of the Hertzian region to obtain a flooded condition. Fig. $10(b-f)$ show a diminishing film thickness as the inlet boundary progressively approaches the Hertzian region. The diminishing film thickness is apparent if one observes that the fringe in the center of the Hertzian region for a given figure is always in the constriction regions in the previous figure. It should also be noted that as starvation progresses, the EHD shape approaches the Hertzian shape. Therefore, the EHD pressure must also approach the Hertzian pressure. In the limit, i.e.s when $h_{0}$ equals zero, the Hertzian shape and pressure are attained.

Some of the experimental and theoretical central film thicknesses are plotted in Figs. 11 and 12 as a function of $x / 2$ where $a$ is the calculated Hertzian radius. Figure 11 shows the effect of various initial film thicknesses for a given load, and Fig. 12 shows the effect of load for a given initial film thickness. The results indicate that film thickness becomes increasingly more sensitive to the inlet boundary as the boundary approaches the Hertzian radius. Indeed, the film thickness approaches zero as the inlet boundary approaches the Hertzian radius. This emphasizes the importance of the inlet region in regards to film thickness. To obtain a flooded condition Fig. 11 shows that the required inlet boundary, expressed as the ratio $x_{b} / a$, increases with film thickness. This reflects the expected. inlet pressure buildup which commences further upstream as the film thickness (and hence speed and/or viscosity) increases. Figure 12 shows the required inlet boundary $x_{p} / a$ to decrease with load. This reflects the overall pressure distribution which must become more Hertzian as the load increases.

The agreement between theory and experiment is quite good when one considers the scatter in the experimental data together with the Grubin assumptions inherent in the theoretical solution, It must also be remembered that the film thickness predicted by theory is subjected to the accuracy of the measured experimental operating conditions, particularly the lubricant properties of $\alpha$ and $\mu_{0}$. It is of interest that the agreement between theory and experiment is no worse for starvation conditions than it is for flooded conditions. In fact, it is likely to be better under starvation conditions since the film shape becomes more like the assumed Hertzian shape when the inlet region is starved. 


\section{Prediction of the Onset of Starvation}

The above results imply that film thickness is determined by the EHD pressure generated in the inlet region and that starvation will initiate when the inlet lubricant boundary approaches the expected location of pressure commencement. The approximate location of pressure commencement can be obtained from the integrated form of Reynolds equation. Neglecting the side-leakage term equation (4) can be integrated to give the reduced pressure gradient

$$
\frac{\partial q}{\partial x}=12 \mu_{0} u\left(\frac{h-h_{0}}{h^{3}}\right)
$$

For constant speed and viscosity the reduced pressure gradient within the inlet region is determined by the geometry term $\left(h-h_{0}\right) / h^{3}$. This term, and therefore the reduced pressure gradient, reaches a maximum when $\mathrm{h} / \mathrm{h}=1.5$ and diminishes approaching zero in the upstream direction $a s \mathrm{~h} / \mathrm{h}$ increases. If $\mathrm{h}_{\mathrm{b}}$ is the thickness of the lubricant film at the inlet boundary (see Fig.9), then it is expected that large values of the inlet geometry ratio $h_{b} / h_{0}$ will pxovide a flooded condition. This is shown in Fig. 13 where all the experimental data are plotted as $h_{0} /\left(h_{0}\right)$ against $h_{b} / h$ where $\left(h_{0}\right)_{f}$ is the film thickness under flooded conditions. The solid curve represents the theoretical results over the experimental range of operating conditions and shows very good agreement with experiment except near the flooded condition. The interesting feature of the results is that the degree of starvation, over a range of loads and initial film thicknesses, can be described by a single curve. The results also show that the flooded condition is approached asymptotically as $\mathrm{h}_{\mathrm{b}} / \mathrm{h}$ increases. Therefore, the onset of starvation cannot be very well defined. However, most of the experimental results indicate a flooded condition at $h_{b} / h_{0}=9$, and the theoretical curve predicts a film thickness which is $95^{\circ}$ percent flooded.

For practical applications a more appropxiate measure of the degree of starvation is the inlet distance $S$ defined as

$$
s \equiv\left(x_{b}-a\right)
$$

and shown diagramatically in Fig. $9 . \mathrm{s}$ can be written in terms of $h_{b} / h_{0}$ as follows: By definition 


$$
\frac{h_{b}}{h_{0}}=\frac{h_{0}+h_{H}}{h_{0}}
$$

where $h_{H}$ is the Hertzian deformation for dry contact (Fig. 1). For point contacts $h_{H}$ can be approximated by (see ref. 5)

$$
h_{H}=\frac{a p_{\max }}{E^{\prime}}\left[3.81\left(\frac{x_{b}}{a}-1\right)^{1.5}\right]
$$

This relation is accurate only for small ratios of $x_{b} / a$. Figure 11 shows that over the experimental range starvation occurs within

$x_{b} / a=4.5$. The calculation of $h_{H}$ from equation (17) for $x_{\mathrm{b}} / \mathrm{a}=4.5$ is about 14 percent less than that calculated from the Hertzian relation ( $\mathrm{Eq} .5$ ). For most EHD conditions starvation occurs within an $x_{\mathrm{p}} / \mathrm{a}$ ratio of 3 or 2 where the error is 7.6 percent and 2 percent, respectively. Now we can write

$$
\left(\frac{x_{b}}{a}-1\right)=\frac{s}{a}
$$

and

$$
\frac{p_{\max }}{E^{\prime}}=\frac{a}{\pi R}
$$

Substituting equations (17), (18) and (19) in equation (16) and solving for $s$ gives

$$
s=\left(\frac{h_{b} / h_{0}-1}{1.21}\right)^{2 / 3} \frac{\left(R_{0} h^{2 / 3}\right.}{a^{1 / 3}}
$$


A similar relation can be derived for EHD line contacts [9]. If the onset of starvation is defined by $h_{b} / h_{0}=9$, then the minimum inlet distance $\mathbf{S}_{f}$ to obtain a flooded condition can be approximated by

$$
s_{f}=\frac{3.52\left(R h_{0}\right)^{2 / 3}}{a^{1 / 3}}
$$

This is very similar to the statement of Fein and Kreutz [17] that the vast majority of pressure buildup for an EHD point contact occurs within about

$$
\frac{3(\mathrm{R} \mathrm{h})^{2 / 3}}{a^{1 / 3}}
$$

ahead of the Hertzian flat.

Figure 14 is a plot of all the starvation results using the inlet distance $s$ as a measure of the degree of starvation. The experimental data is represented by four curves each showing the film thickness approaching zero as the inlet distance approaches zero. Each curve contains the data for all three test loads thus indicating that starvation is not very sensitive to load. This is consistent with the view that film thickness is primarily determined by the EHD pressure generated in the inlet region. The primary effect of load is merely to alter the size of the Hertzian region and the magnitude of the pressure therein. Load has only a secondary influence on the EHD pressure generated in the inlet region. Therefore, this pressure, and hence the film thickness determined by this pressure, will remain essentially the same regardless of load.

The onset of starvation given by equation (21) is plotted in Fig. 14 for each test load. It compares very well with the experimental results. An interesting feature is that for a given central film thickness $h$, equation (2l) predicts that starvation will commence at slightly smaller inlet distances when the load increases. The experimental data also reveals this tendency. This variation with load occurs because the gap thickness increases with load for a constant $s$ and $h_{0}$, thus making the ratio $h_{b} / h_{0}$ larger.

Also plotted in Fig. 14 is the line defining the equation

$$
\mathrm{s}=500 \mathrm{~h}_{\mathrm{o}}
$$


Over the experimental operating conditions this equation approximates the onset of starvation and indicates the relative magnitude of the dimensions involved.

Semi-Empirical Formula for Starvation

All the starvation results are replotted in Fig. 15 where $\mathrm{s} / \mathrm{s}_{\mathrm{f}}$, as a dimensionless starvation parameter, now represents the degree of starvation. The experimental data can be approximated by a quadrant of a circle, i.e.,

$$
\frac{h_{0}}{\left(h_{o}\right)_{f}}=\left[\frac{s}{S_{f}}\left(2-\frac{s}{S_{f}}\right)\right] I / 2
$$

This can be employed in equation (11) to provide the following semiempirical film thickness formula which includes the effects of starvation

$$
\frac{h_{0}}{R}=1.73\left[\frac{S}{S_{f}}\left(2-\frac{S}{S_{f}}\right)\right]^{I / 2}\left(\frac{\alpha \mu_{o} u}{R}\right)^{5 / 7}\left(\frac{w}{E^{\prime} R^{2}}\right)^{-I / 21}
$$

The greatest practical problem in applying equation (24) is the determination of the inlet distance for the particular application. The inlet distance is difficult to measure directly and difficult to predict from external conditions. Besides the method and amount of lubricant supplied, these external conditions must involve those aspects which deal with the transport and distribution of lubricant within the bearing, i.e. viscosity, surface tension, bearing dynamics, and geometry. There is certainly a great need for practical research along these lines.

\section{EFFECT OF STARVATION ON OTHER ASPECTS OF EHD}

\section{Friction}

Friction arises from the viscous shear forces acting on the bearing surfaces. For EHD contacts rolling friction is associated with the pressure generation in the inlet region, and sliding friction, or traction, is associated with the flat Hertzian region and is inversely proportional to the central film thickness $h_{0}$. A starved inlet region inhibits the inlet pressure buildup and reduces the central film thickness. Therefore, a reduction in rolling friction and an increase in sliding friction, or traction, is expected to accompany starvation. Both these effects have practical implications. In rolling element bearings, for example, it is desirable to have low rolling friction and high traction. The latter is important for preventing slip, and hence bearing failure, between the rolling elements and raceways. 
Pressure and Stress Distribution

It was shown in Fig. 10 that as starvation progresses the EHD film shape approaches the Hertzian shape. Thus, it should follow that the pressure distribution and therefore the stress distribution will also approach the Hertzian condition.

\section{ADDITIONAI EXXERIMENTS}

Cavitation

Ordinary lubricants contain about 10 percent (by volume) of dissolved gas or air at atmospheric pressure. When the lubricant pressure is reduced below the saturation pressure in the exit region the dissolved gas diffuses into small gas bubbles within the lubricant causing the bubbles to grow in size. This form of bubble growth, described by Schweitzer and Szebehely [18] and Floberg [19], is the usual form of cavitation which occurs in lubricating films.

The cavitated region, under slow speeds, may often be contained within the lubricant meniscus surrounding the contact region. At very slow speeds it may consist of a single gas bubble like that observed by Archard and Kirk[20]; or, at higher speeds it may develop into a large number of gas bubbles. If the bearing is stopped, the bubbles often coalesce into a single bubble which detaches itself from the contact region and slowly goes back into solution as it moves downstream. This is shown in Fig. 16. Figure 16(a), which was taken about one second after the bearing had stopped, shows a bubble just prior to its separation from the contact region. Figure $16(\mathrm{~b})$ shows a bubble approximately two seconds after the bearing had stopped. An interesting feature is the interference pattern which has developed, apparently between the glass race and the surface of the gas bubble. It indicates an "EHD" film which has the features of the classical EHD point contact shape. Both the lateral and rear constrictions are visible as well as the slight increase in film thickness must prior to the rear constriction.

Under normal bearing speeds the cavitated region breaks through the lubricant meniscus on the downstream side, thus exposing itself to the atmosphere. This has little effect on the general appearance of the cavitated pattern. The lubricant which passes through the Hertzian region generally ruptures at a film thickness which is about 1.5 times the centra. film thickness. The cavitation pattern consists of thin ribs of lubricant separated by air spaces. This is most clearly seen for large central film thicknesses like that shown in Fig. 17( $\mathrm{a})$. 
The Iubricant which escapes around the Hertzian region ruptures into cavitation fingers which grow perpendicular to a line which makes an angle of $35^{\circ}$ with the direction of motion. The shape of the cavitation fingers is partially determined by surface tension. A high surface tension fluid causes the cavitation fingers to become more rounded. This is shown in Fig. 17(b) where the lubricant is glycerol. It has a surface tension of $63 \mathrm{dynes} / \mathrm{cm}$ which is twice that of most lubricating oils. The small bubble to the right of the Hertzian region has cavitated prematurely. This may be due to a foreign particle within the fluid which has provided a preferential nucleating site for cavitation to take place.

The lubricant in Fig. $17(\mathrm{c})$ is $\mathrm{a}$ concentrated dispersion of very fine colloidal graphite (Oildag) in SAE 30 oil. These graphite particles provide additional nuclearing sites thus causing the branches to form on the cavitation fingers.

In most bearing applications a cavitated outlet region is immediately followed by an inlet region. The influence of the cavitated region on the lubricant supply condition in the inlet region is an important practical aspect which is often overlooked. It is of interest, therefore, to consider the distribution of lubricant within the cavitated region.

The relative shift of the interference fringes due to the different refractive indices of air and oil indicate the distribution of lubricant within the cavitated region. Figure 18(a) shows schematically the distribution of lubricant within the cavitated region at a constant radius from the ball center ( $i . e_{0}$, where the gap thickness is constant). The individual air spaces, as well as the ribs of lubricant, within the ball track essentially extend across the gap between the bearing surfaces. After the ball has passed, the glass race is left with the situation shown schematically in Fig. 18(b). Narrow ribs of lubricant remain on the track while thin waves of lubricant form adjacent to the track. The same general lubricant distribution, though somewhat flattened out, appears in the inlet region. Unless this track is filled in, it is this depleted supply of lubricant which must provide a sufficient quantity of lubricant in the inlet region to maintain a flooded condition. If the design of a bearing and the method of lubricant supply do not fulfill the local lubricant requirements in the inlet region, the bearing may be operating under starved conditions even though it is "well lubricated".

\section{Entrapment}

An oil entrapment between the ball and glass race is shown in Fig. 19(a). The surfaces are in contact (or very nearly so) only along the edge of the Hertzian region. The fringes, which are of a monochromatic 
green system, indicate a wedge-shaped film shown schematically in Fig. $19(\mathrm{~b})$.

The particular shape of the entrapment and its formation is someWhat different from the normal approach entrapments described by other workers $[16,21-23]$ 。 The bearing was rotated slowly in a viscous lubricant (IUB D) and then stopped by applying a breaking torque. The wedge-shaped film is probably the result of a decreasing surface speed. which generated a thinner film in the inlet region as the motion was stopped. The braking torque produced a slight reverse motion equal to about one-fourth the Hertzian diameter. This caused some of the fluid to leak out and produced the crescent-shaped ridge in the film thickness along the right-hand edge of the Hertzian region.

The photomicrograph was taken approximately five minutes after the entrapment was formed. During that time some of the lubricant leaked out around the edge of the Hertzian region and along the scratches in the bearing surfaces. These results imply that in a bearing application where there is a velocity reversal it is possible to maintain a full EHD film even though the relative surface velocity is momentarily zero.

Grease Lubrication

Figure 20 is a plot of film thickness against speed for three Iithium hydroxystearate soap greases and their base oils. The base oil viscosity and soap content of the greases are given in table 2. Each grease gives a higher film thickness than its base oil thus indicating that the apparent viscosity of the grease is greater than the base oil viscosity, even at very high rates of shear (10 $\mathrm{sec}^{-1}$ ). It is also noted that the grease G2 with 10.5 percent soap content gives a greater film thickness than the grease G3 with 6 percent soap content. This is in line with recent work by Dyson and Wilson [24] on the same greases which indicated that the soap breaks down into hard spheroidal particles. These particles have a thickening effect on the base oil which prevents the apparent discosity from reaching the base oil viscosity.

A comparison of the grease and oil film shapes undex moderate speeds showed no noticeable difference, provided they were compared at the same nominal film thickness. At extremely slow speeds, however, relatively thick and irregular films were observed with grease particularly when operating in fresh grease. These films remained under static conditions as shown in Fig. 21. Figure 21(a) was obtained after the ball had been rolled very slowly in fresh grease (GI). The fringes within the Hertzian region are very irregular in.. shape, thus indicating a nonuniform film shape or possibly large changes in refractive index due to the heterogeneous structure of the grease. 
Figure 2l(b) was obtained after the ball had been rolled several times over the same track. The resulting film is thinner (note the position of the black fringe in each photomicrograph) and more uniform, thus suggesting a breakdown in soap structure. It is possible that the small circular spots in Fig. 2l(b) are broken down soap particles. It was only possible to obtain a film of the thickness shown in Fig. 2l(a) by resupplying the bearing with unworked grease.

A test, run at constant speed, showed no change in film thickness with grease GI over a period of 30 minutes. It is likely, therefore, that most of the soap structure had broken down soon after the bearing was started. The test was terminated after 45 minutes when the film thickness became clearly affected by starvation. This was always found difficult to avoid.

Starvation tests performed with grease G2 and its base oil showed no apparent difference in the way the film thickness diminishes with the inlet distance from its initially flooded value. Important differences, however, between grease and oil lubrication in connection with starvation are likely to be found in the mechanisms by which the Iubricant is transported and redistributed in the vicinity of the inlet region.

BaII Spin

Figure 22 shows two photomicrographs taken with the top race of the thrust bearing held stationary. The quality of the image is lacking because at high object speeds the flash duration is not short enough to prevent image blur. In Fig. 22(a), where the cage speed is $263 \mathrm{rpm}$, the film shape and wake pattern are similar to that found when the bearing is operating in a counterrotation manner. Figure 22 (b) was taken when the cage speed was increased to $300 \mathrm{rpm}$. Both the film shape and wake pattern are skewed on the order of $15^{\circ}$ away from the orbital direction of the ball. This can be attributed to a gyroscopic moment which produces a sliding velocity component in the transverse direction. The gyroscopic moment in Fig. 22(a) is resisted by the frictional forces at the cage and bearing races. This requires an effective coefficient of friction of 0.02 for the particular operating conditions [9].

\section{Edge Effects in Line Contact}

Preliminary work was carried out on a tapered roller thrust bearing where the top glass race was held stationary and the interference fringes were observed stroboscopically. In Fig. 23(a) the deformation of the glass beyond the roller end causes an additional compressive stress at the roller end which produces the characteristic "dog bone" shape. Also, a very predominant lateral constriction in film thickness 
can be seen at the contact edge. This can be attributed to sideleakage effects, primarily in the inlet region.

The edge effects can be reduced by blending the roller ends, as shown by Gohar and Cameron [25], or crowning the roller profile. A roller with a blended end is shown in Fig. 23(b). The central film thickness is the same as that in Fig. 23(a) but the lateral constriction has almost been eliminated.

Some interesting implications arise from the film shapes in Fig. 23. The film shape at the edge of the blended roller is very similar to that found in point contacts. Even the cavitation pattern along the edge is similar to the point contact case. In this respect, point contacts can be considered as "naturally" blended or crowned. While point contacts may not have the optimum crown to eliminate the lateral constrictions, it is possible that an elliptical contact found, for example, between a ball and grooved raceway may provide the required geometry for its elimination. These results further imply that the lateral constriction for an unblended roller, as found in Fig. 23(a), may be far more severe than those associated with point contacts.

\section{CONCLUSIONS}

Starvation under EHD conditions is associated with the location of the lubricant boundary in the inlet region. Under starvation conditions the local film thickness in the Hertzian region is a function of the lubricant boundary immediately upstream. The results show that the onset of starvation is reflected in the expected location of pressure commencement, and that film thickness diminishes to zero as the lubricant boundary approaches the Hertzian region. This implies that film thickness is established by the HHD pressure generated in the inlet region. The primary effect of starvation is that it inhibits the generation of this pressure. The effect of this was measured in terms of film thickness and was found to be in harmony with EHD theory based on Grubin assumptions.

Under constant operating conditions the hydrodynamic pressure generation is a function of the inlet gap geometry. The ratio $\mathrm{h} / \mathrm{h}$. describes the relative thickness of this gap and reflects the relative magnitude of the hydrodynamic pressure generation along the inlet region. The experimental results correlate with the inlet geometry ratio $h_{b} / h_{0}$ where $h_{b}$ is the gap thickness at the lubricant boundary. The onset of starvation is not very well defined, but can be approximated by $h_{b} / h_{0}=9$. This can be used to derive the onset 
of starvation in terms of the inlet distance $s$ which is the dis tance between the lubricant boundary and the edge of the Hertzian region. If the location of the inlet boundary is known, film thickness can be predicted theoretically or by a semi-empirical formula. based on the experimental results.

Film thickness is only one aspect of starvation. The suppression of hydrodynamic pressure by starvation causes the overall pressure and stress distribution to conform to the Hertzian condition. It also reduces rolling friction and increases traction. Because these aspects have practical implications, starvation should not be considered as just a situation to avoid, but should be dealt with as an additional EHD parameter which can be usefully employed.

\section{Acknowledgements}

The authors would like to thank the Science Research Council for a grant; the Hoffmann Bearing Company, Chelmsford, Essex for their high quality steel balls; the British Timken Bearing Company, Northants for the tapered rollers and race; and the Shell Research limited of Thornton for the calibrated IUB D and the greases.

\section{References}

1. Grubin, A. N. and Vinogradova, I. E., "Investigation of the Contact of Machine Components," CTS-235, 1949, Department of Scientific and Industrial Research, Great Britain.

2. Crook, A. W., "The Lubrication of Rollers," Philosophical Transactions of the Royal Society, Ser. A, Vol. 250, 1958, pp. 387-409,

3. Cheng, H. S. and Sternlicht, B., "A Numerical Solution for the Pressure, Temperature, and Film Thickness Between Two Infinitely Long, Lubricated Rolling and Sliding Cylinders Under Heavy Loads," Journal of Basic Engineering, Vol. 87, No. 3, Sept. 1965, pp. 695707 .

4. Dowson, D. and Whitaker, A. V., "A Numerical Procedure for the Solution of the Elastohydrodynamic Problem of Rolling and Sliding Contacts Lubricated by a Newtonian Fluid," Proceedings of the Institute of Mechanical Engineers, Vol. 180, Part 3B, 1965-66, p, 57.

5. Cameron, A., The Principles of Lubrication, Wiley, New York, 1966.

6. Cameron, A. and Gohar, R., "Theoretical and Experimental Studies of the Oil Film in Lubricated Point Contacts," Proceedings of the Royal Society (London), Ser. A, Vol. 291, No. 1427, Apr. 26, 1966, pp. 520-536. 
7. Archard, J. F. and Kirk, M. T., "Lubrication at Point Contacts," Proceedings of the Royal Society (London), Ser. A, Vol. 261, 1961, pp. 532-550.

8. Cheng, H. S., "A Numerical Solution of the Elastohydrodynamic Film Thickness in an Elliptical Contact," Journal of Lubrication Technology, Vol. 92, No. 1, Jan. 1970, pp. 155-162.

9. Wedeven, L. D., "Optical Measurements in Elastohydrodynamic Rolling Contact Bearings," Ph.D. Thesis, 1970, London, England.

10. Foord, C. A., Wedeven, I. D., Westlake, F. J., and Cameron, A., "Optical Elastohydrodynamics," Institute of Mechanical Engineers Meeting, Feb. 4, 1970.

11. Glasstone, S., Textbook of Physical Chemistry, 2nd ed., Van Nostrand, New York, 1946.

12. Chu, P. S. Y. and Cameron, A., "Compressibility and Thermal Expansion of Oils," Journal of the Institute of Petroleum, Vol. 49, No. 473, May 1963, pp. 140-145.

13. Galvin, G. D., Naylor, H., and Wilson, A. R., "The Effect of Pressure and Temperature on Some Properties of Fluids of Importance in Elastohydrodynamic Lubrication," Proceedings of the Institute of Mechanical Engineers, Vol. 178, Part 3N, 1963-64, pp. 283-290.

14. Gohar, R., "A Ball-and-Plate Machine for Measuring Elastohydrodynamic $0 i 1$ Films," Proceedings of the Institute of Mechanical Engineers, Vol. 182, Part 3G, 1967-68, pp. 43-45.

15. Dyson, A., Naylor, H., and Wilson, A. R., "The Measurement of OilFilm Thickness in Elastohydrodynamic Contacts," Proceedings of the Institute of Mechanical Engineers, Vol. 180, Part 3B, 1965-66, p. 119 .

16. Foord, C. A., Hammann, W. C., and Cameron, A., "Evaluation of Lubricants Using Optical Elastohydrodynamics," ASLE Transactions, Vol. 11, No. 1, Jan. 1968, pp. 31-43.

17. Fein, R. S. and Kreutz, K. L., "Discussion of Boundary Lubrication," Interdisciplinary Approach to Friction and Wear, SP-181, 1967, NASA, Washington, D.C., pp. 364-366.

18. Schweitzer, P. H. and Szebehely, V. G., "Gas Evolution in Liquids and Cavitation," Journal of Applied Physics, Vol. 21, No. 12, No. 12, Dec. 1950, pp. 1218-1224.

19. Floberg, I., "Sub-Cavity Pressures and Number of Oil Streamers in Cavitation Regions with Special Reference to the Infinite Journal Bearing," Acta Polytechnica Scandinavica, Mechanical Engineering Series, No. 37, 1968. 
20. Archard, J. F. and Kirk, M. T., "Influence of Elastic Modulus on the Lubrication of Point Contacts," Paper 15, Institute of Mechanical Engineers Lubrication and Wear Convention, 1963, pp. 181-189.

21. Dowson, D. and Jones, D. A., "An Optical-Interference Method of Measurement of Time-Dependent Elastohydrodynamic Film Profiles," Proceedings of the Institute of Mechanical Engineers, Vol. 182, Part 3G, 1967-68, pp. 49-52.

22. Westlake, F. J. and Cameron, A., "A Study of Ultra-Thin Lubricant Films Using an Optical Technique," Proceedings of the Institute of Mechanical Engineers, Vol. 182, Part 3G, 1967-68, pp. 75-78.

23. Christensen, H., "The Oil Film in a Closing Gap," Proceedings of the Royal Society (London), Ser. A, Vol. 266, NNo. 1326, Mar. 20, 1962, pp. 312-328.

24. Dyson, A. and Wilson, A. R., "Film Thickness in Elastohydrodynamic Lubrication of Rollers by Greases," Institute of Mechanical Engineers Symposium on the Use of Grease as an Engineering Component, London, Feb. 19-20, 1970.

25. Gohar, R. and Cameron, A., "The Mapping of Elastohydrodynamic Contacts," Paper 66LC-2I, Oct. 1966, ASLE, Park Ridge, III. 
TABLE I. - PROPERTIES OF TEST LUBRICANTS

\begin{tabular}{|c|c|c|c|c|c|}
\hline \multirow{2}{*}{$\begin{array}{c}\text { Iubricant } \\
\text { symbol }\end{array}$} & \multirow{2}{*}{$\begin{array}{l}\text { Specific } \\
\text { gravity }\end{array}$} & \multicolumn{3}{|c|}{ Viscosity, es } & \multirow{2}{*}{$\begin{array}{c}\text { Pressure-viscosity } \\
\text { coefficient } \\
\left(p s i^{-1}\right)\end{array}$} \\
\hline & & $75^{\circ} \mathrm{F}$ & $100^{\circ} \mathrm{F}$ & $210^{\circ} \mathrm{F}$ & \\
\hline $\begin{array}{l}\text { SAE } 10 \\
\text { SAE } 30 \\
\text { SAE } 40 \\
\text { TN } 631 \\
\text { LUB D }\end{array}$ & $\begin{array}{r}0.870 \\
.883 \\
.885 \\
.901 \\
.942\end{array}$ & $\begin{array}{r}66.8 \\
261.0 \\
401.0 \\
572.0\end{array}$ & $\begin{array}{l}33.9 \\
113.0 \\
165.0 \\
138.0 \\
182\end{array}$ & $\begin{array}{r}5.2 \\
11.4 \\
14.8 \\
10.2 \\
10.8\end{array}$ & $\begin{array}{l}1.41 \times 10^{-4} \\
1.60 \\
1.70 \\
2.14 \\
2.50\end{array}$ \\
\hline
\end{tabular}

TABLE II. - PROPERTIES OF LITHIUM

\section{HYDROXYSTEARATE SOAP GREASES}

\begin{tabular}{|c|c|c|c|}
\hline $\begin{array}{c}\text { Grease } \\
\text { designation }\end{array}$ & $\begin{array}{c}\text { Soap } \\
\text { content, } \%\end{array}$ & \multicolumn{2}{|l|}{ Base oil viscosity, cs } \\
\cline { 2 - 4 } & & $100^{\circ} \mathrm{F}$ & $210^{\circ} \mathrm{F}$ \\
\hline GI & 10.5 & 33.23 & 4.74 \\
G2 & 10.5 & 133.5 & 10.07 \\
G3 & 6 & 133.5 & 10.07 \\
\hline
\end{tabular}




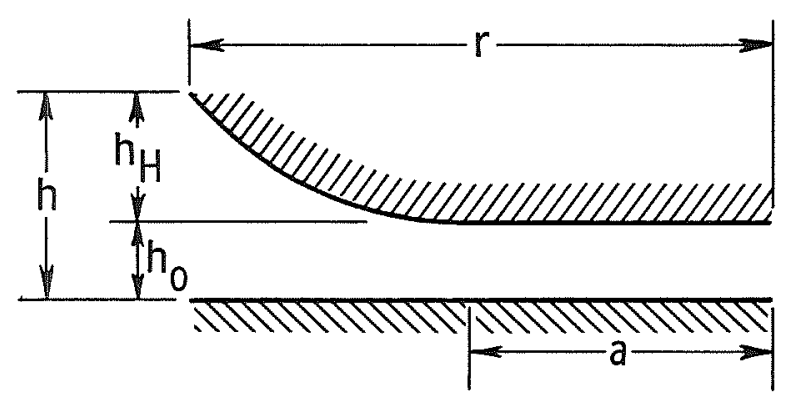

(a)

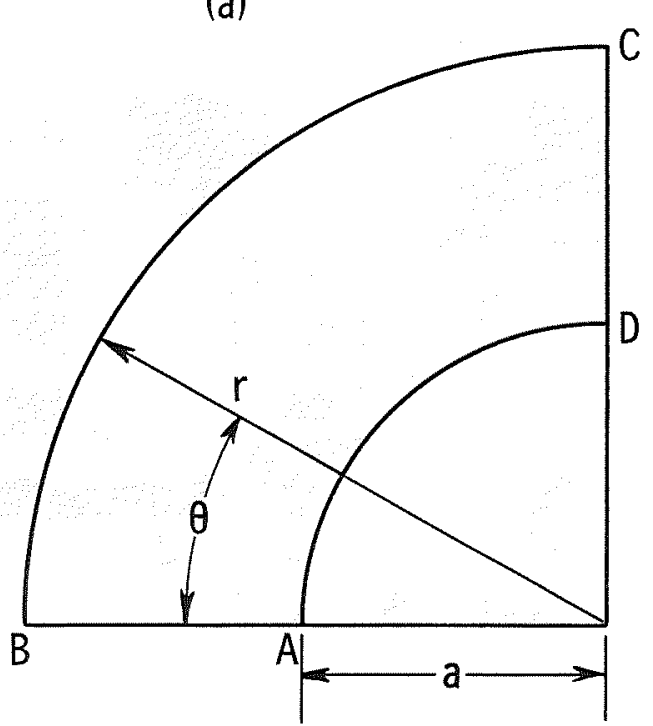

(b)

Figure 1. - Contact geometry.

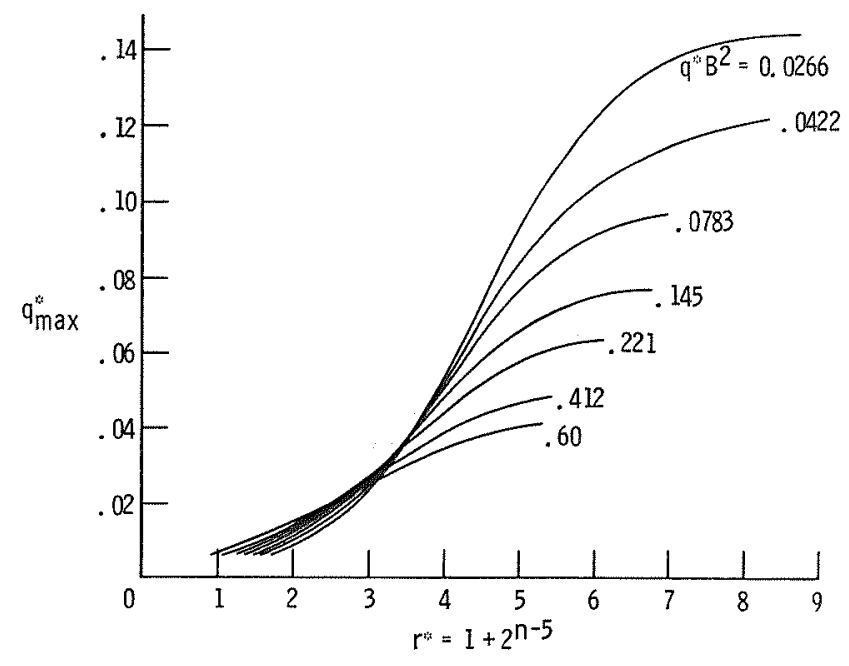

Figure 2. - Theoretical results for starvation.

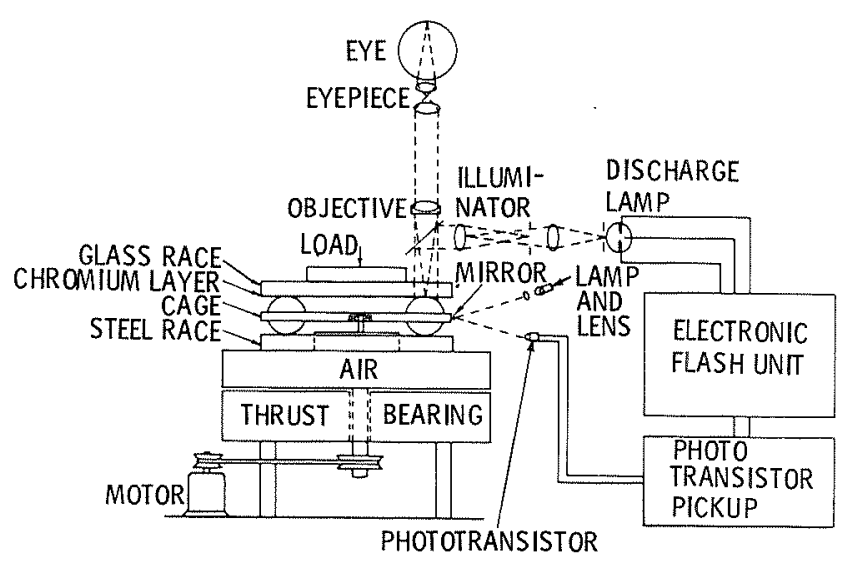

Figure 3. - Schematic diagram of apparatus. 


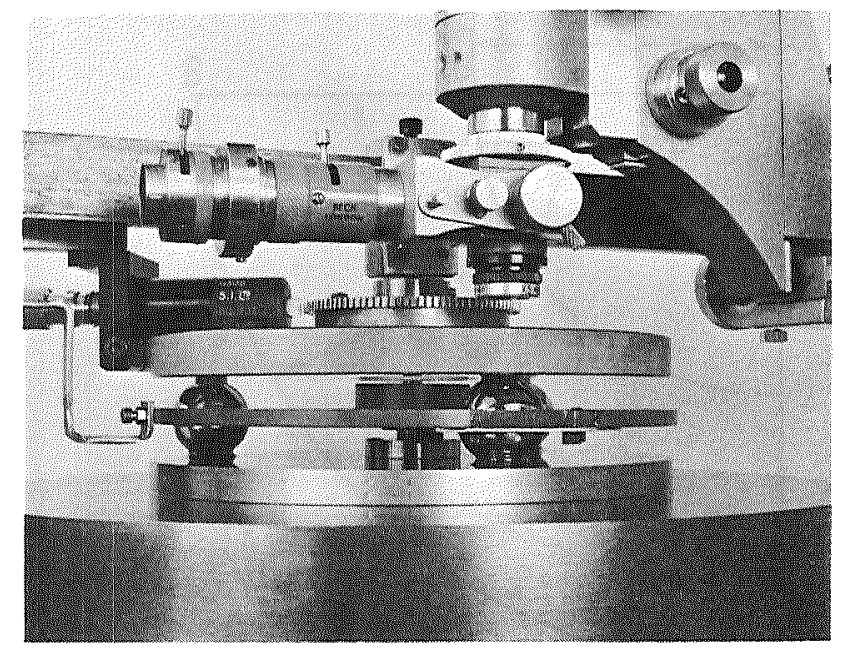

Figure 4. - Experimental ball thrust bearing with stationary cage.

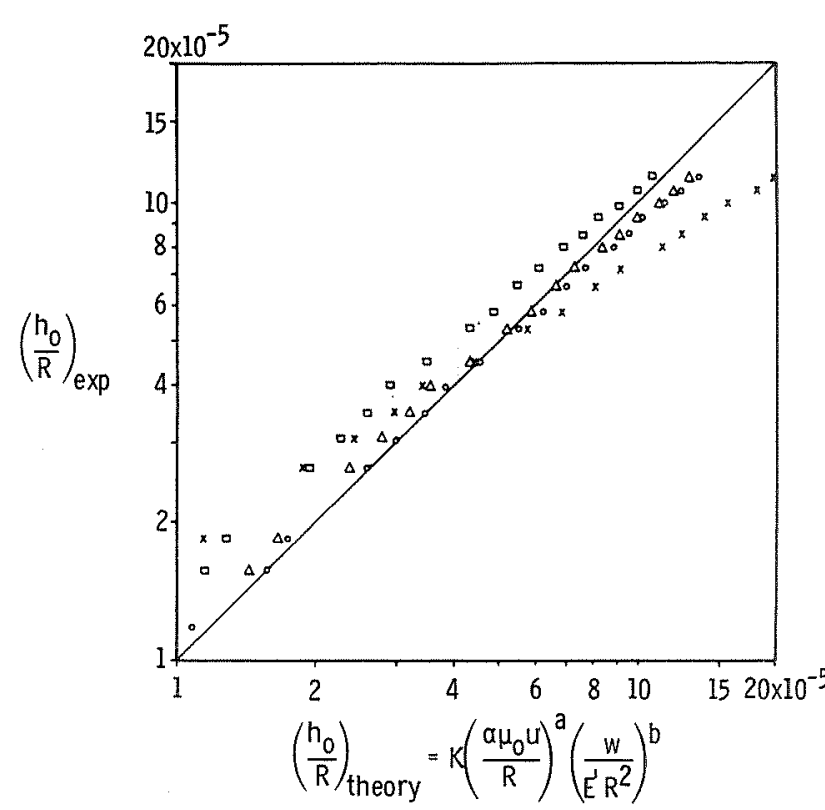

SYMBOL SOURCE THEORETICAL CONSTANTS

\begin{tabular}{lllll} 
& & \multicolumn{1}{c}{$K$} & \multicolumn{1}{c}{$a$} & $\mathrm{~b}$ \\
$\times$ & ARCHARD \& COWKING & 1.4 & 0.74 & -0.074 \\
$\triangle$ & CAMERON \& GOHAR & 3 & 1 & -.33 \\
$\therefore$ & CHENG & 1.69 & .725 & -.058 \\
& EQUATION (11) & 1.73 & .714 & -.048
\end{tabular}

Figure 5. - Comparison of point contact theories with experiment. 

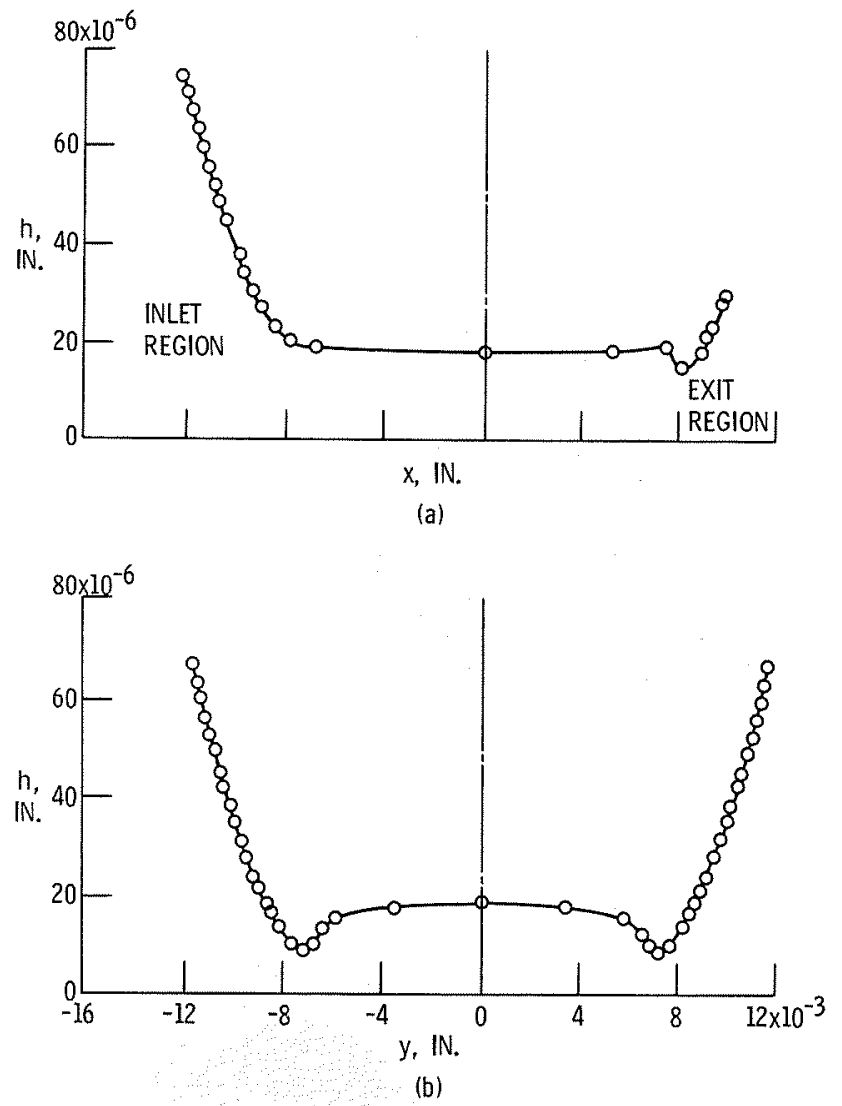

Figure 6. - Measured film shape (a) along the centerline in the direction of motion, and (b) in the transverse direction at the location of minimum film thickness; $u=2.74 \mathrm{in} . / \mathrm{sec}$; $\mu_{0}=80 \times 10^{-6}(\mathrm{lbf})(\mathrm{sec}) / \mathrm{in} .{ }^{2}, \alpha=2.5 \times 10^{-4} \mathrm{psi}^{-1}, w=12 \mathrm{lbf}$, $\mathrm{p}_{\text {max }}=87000 \mathrm{psi}$
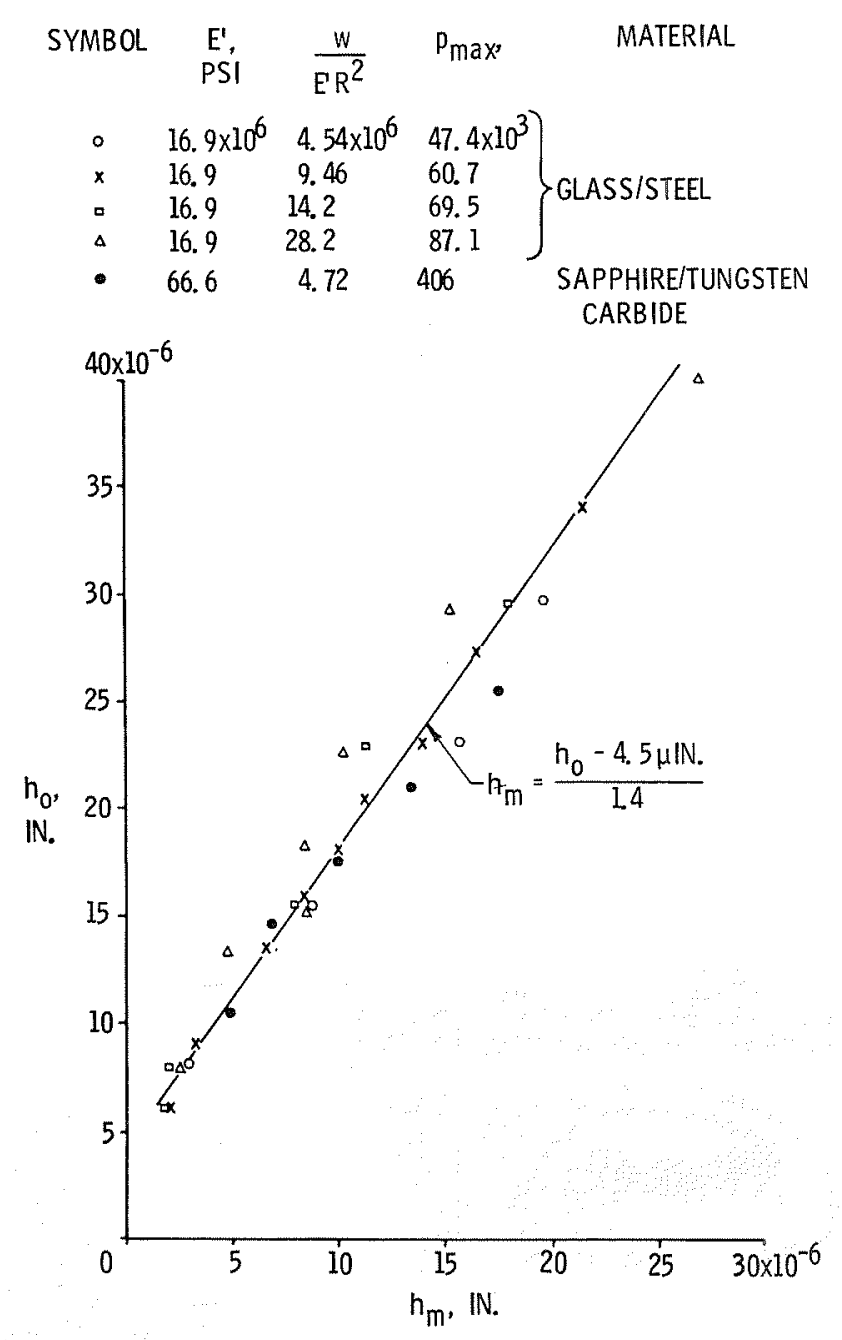

Figure 7. - Plot of the central film thickness versus minimum film thickness for a range of experimental conditions. 

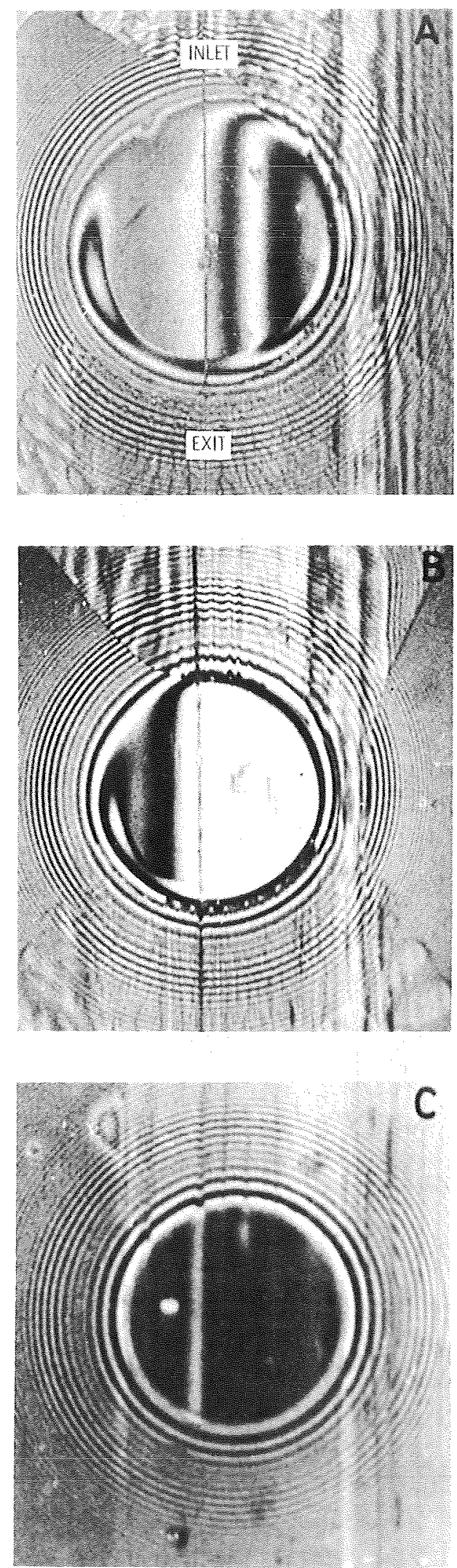

Figure 8. - Effect of inlet lubricant boundary on film shape.

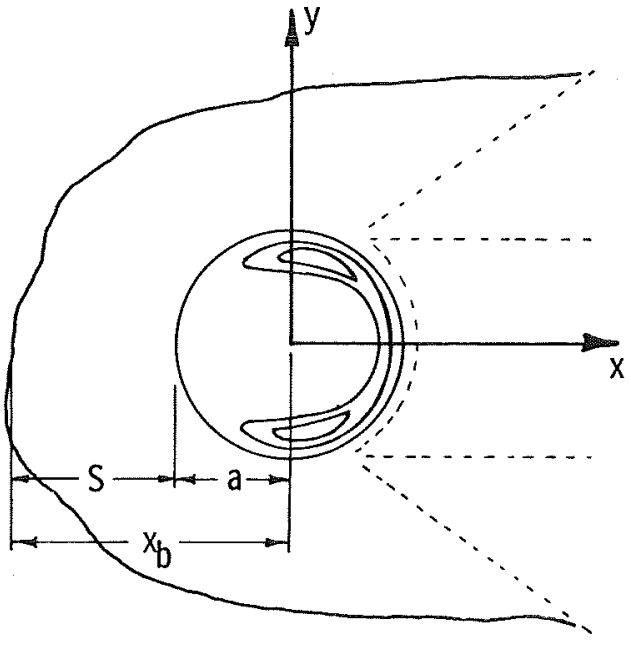

1
1
0
0
0
10

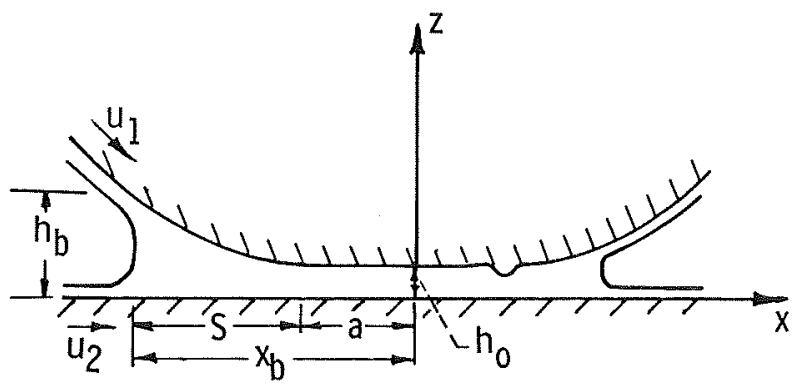

(b)

Figure 9. - Contact geometry showing required measurements for starvation; (a) plan view, (b) crosssectional view along centerline. 

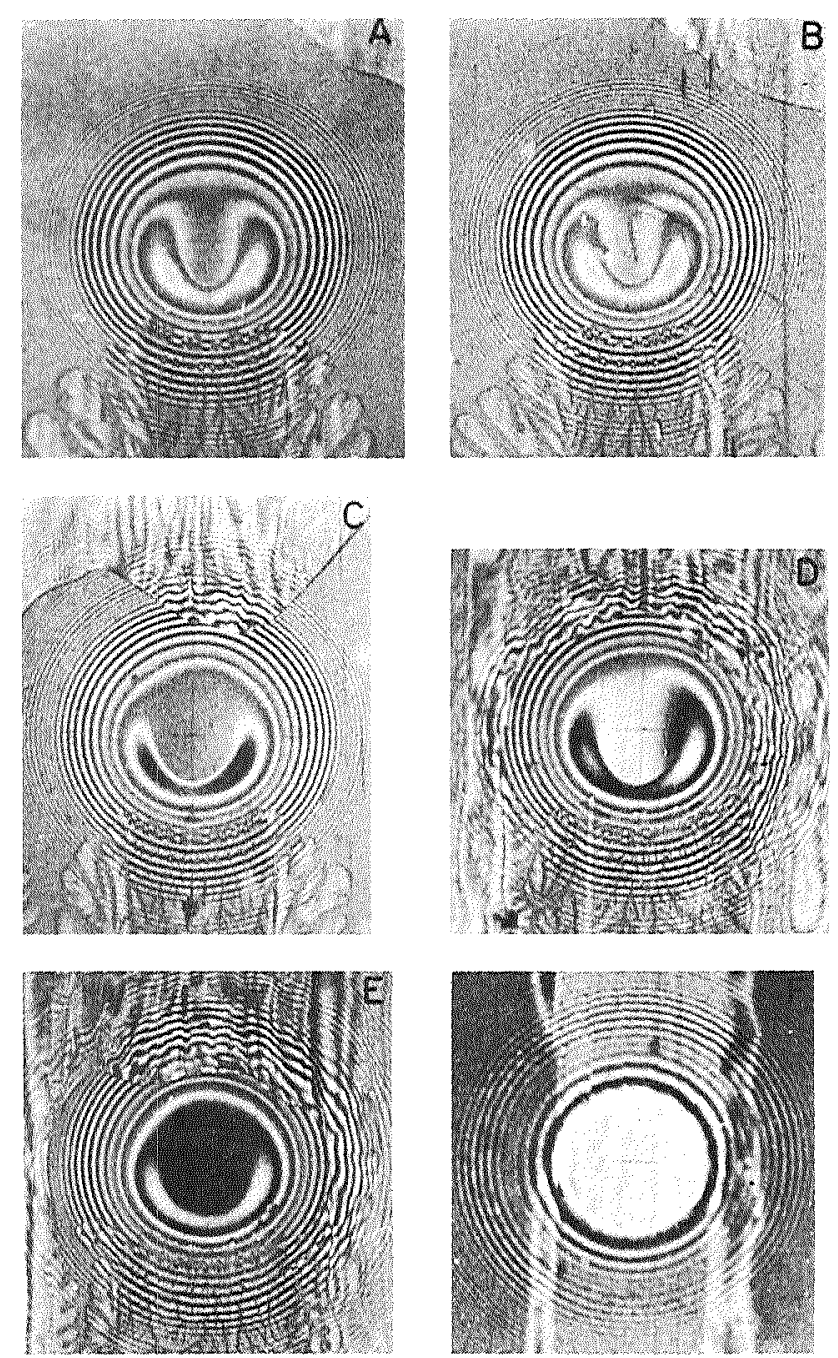

Figure 10. - Photomicrographs showing progressive starvation.

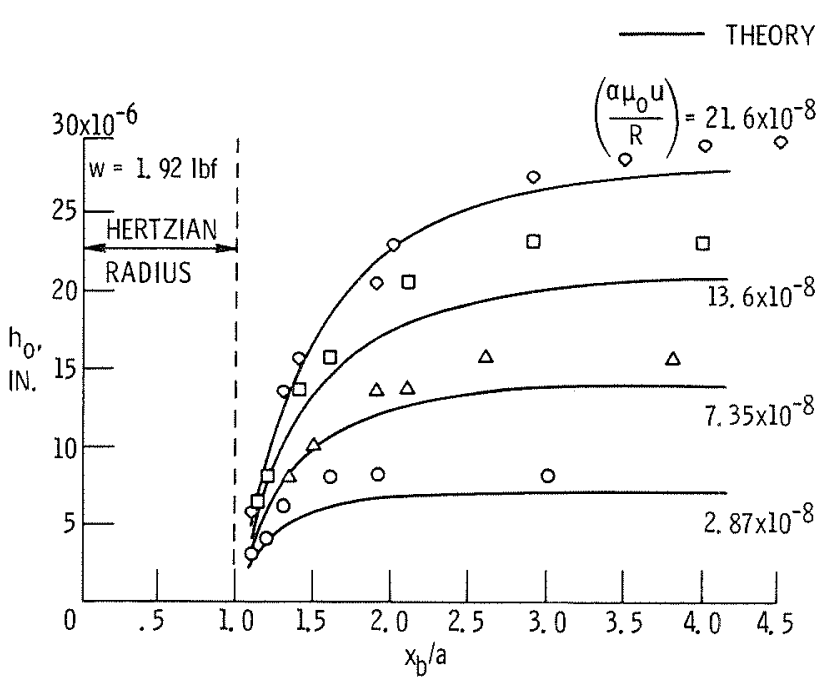

Figure 11. - Effect of inlet boundary on film thickness for different initial film thicknesses.

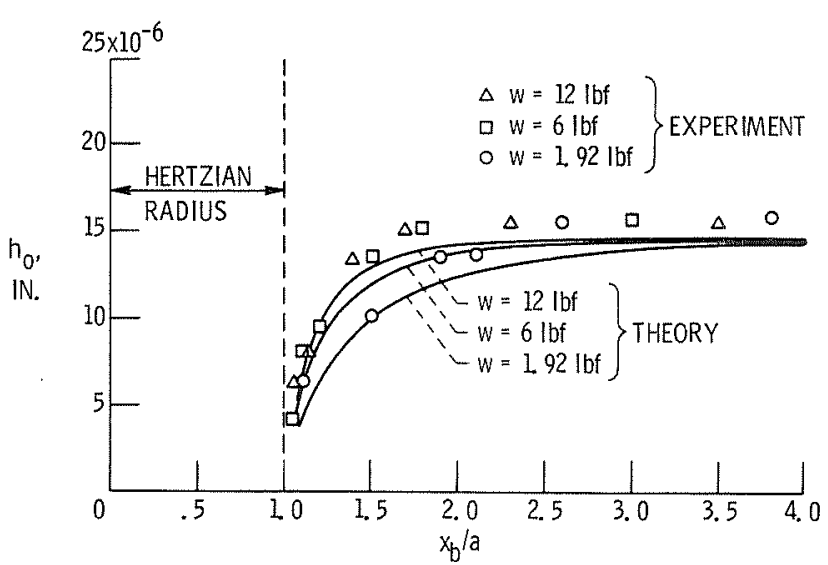

Figure 12. - Effect of inlet boundary on film thickness for different loads. 


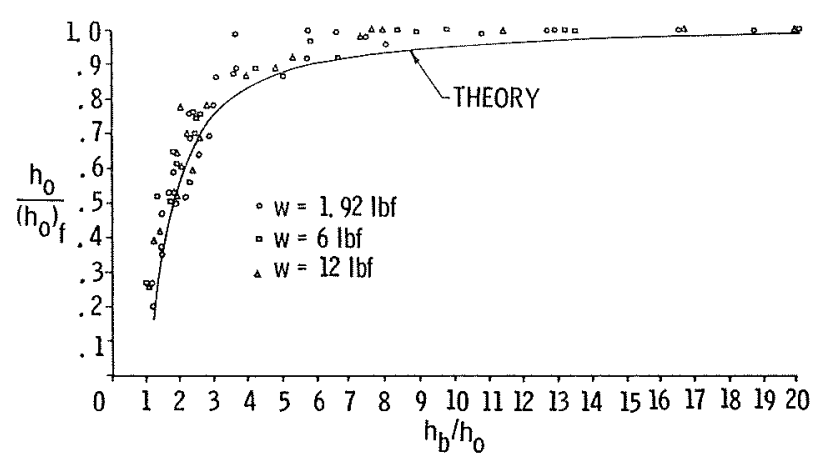

Figure 13. - Comparison of theory and experiment for all the starvation results using the inlet geometry ratio $h_{b} / h_{0}$.

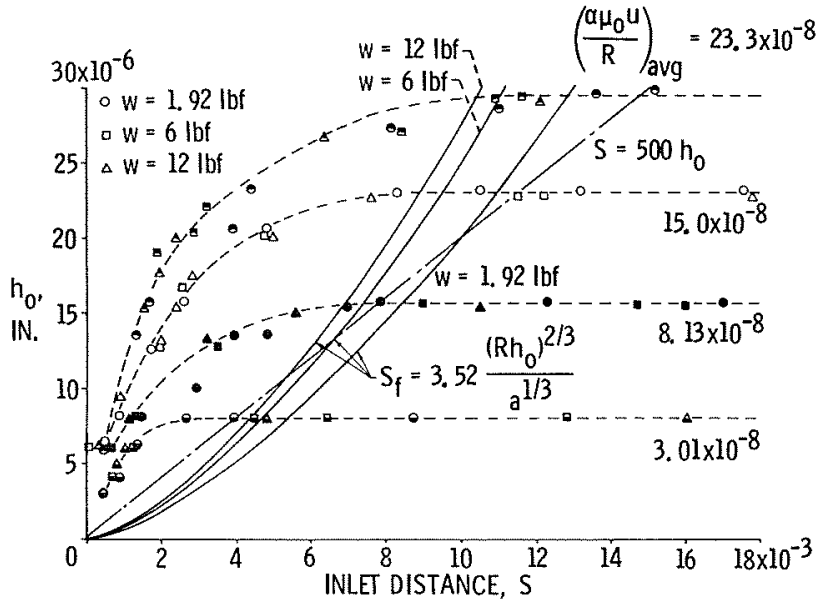

Figure 14. - Experimental results plotted as film thickness against inlet distance.

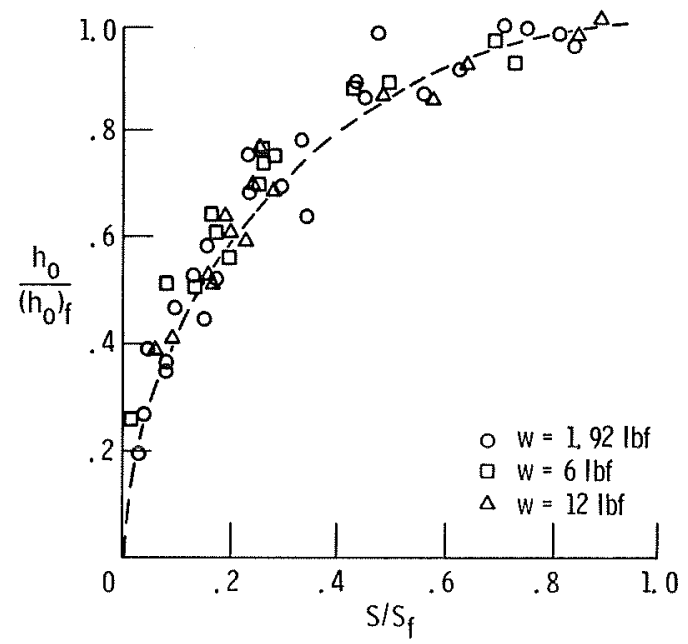

Figure 15. - The degree of starvation as a function of the starvation parameter $S / S_{f}$. 

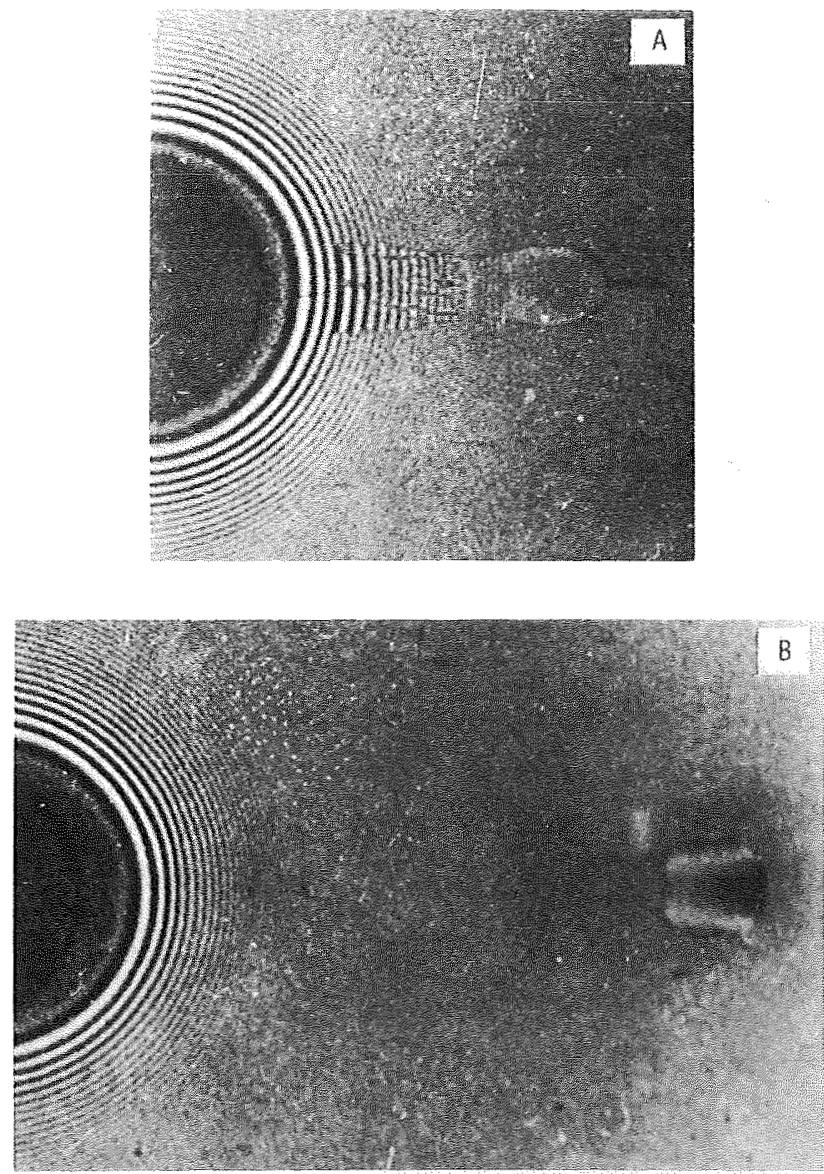

Figure 16. - Coalescence and separation of the cavitation bubbles: (a) about one second after bearing stopped, (b) about two seconds after bearing stopped showing the "EHD lubrication" of an air bubble.
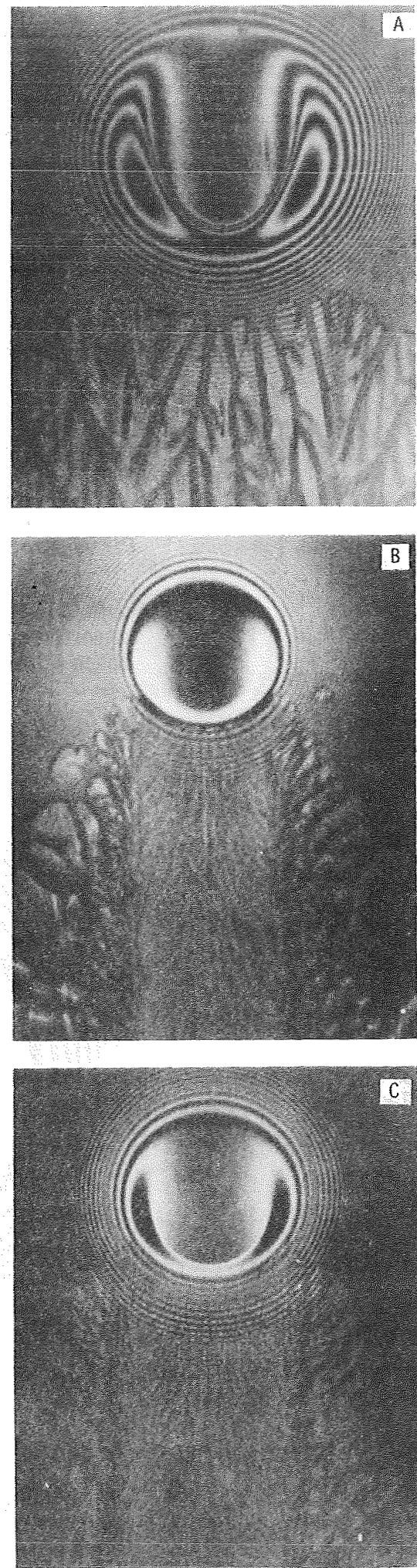

Fiqure 17. - Cavitation pattern in rolling point contact: (a) for large film thickness $h_{0}=67$ microinches) showing striations of air and oil, (b) for high surface tension fluid (glycerol), and (c) for a concentrated dispersion of colloidal graphite (Oildag). 


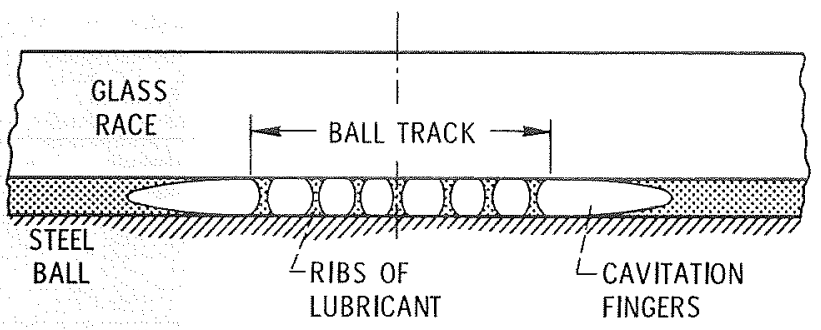

(a)

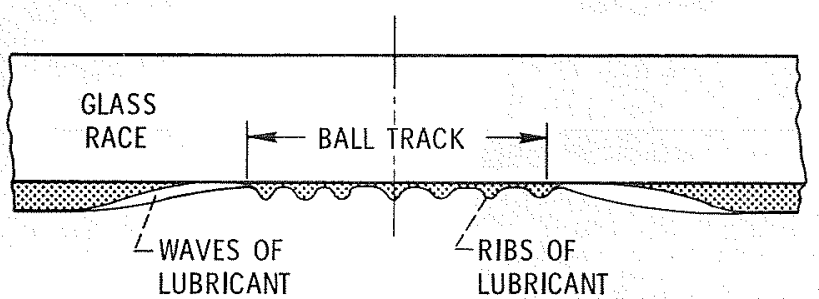

(b)

Figure 18. - Schematic representation of the cavitated region: (a) at a constant radius from the ball center, and (b) showing the distribution of lubricant after the ball has passed.
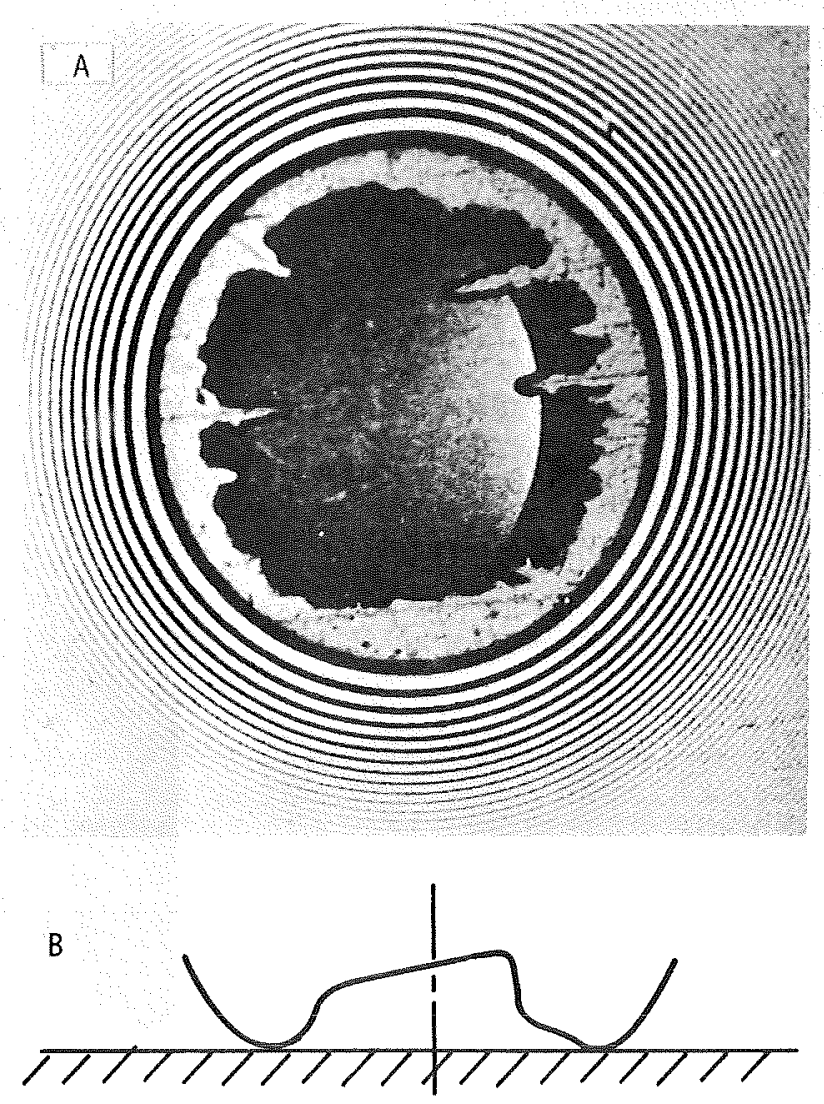

Figure 19. - (a) Photomicrograph of an oil entrapment; (b) schematic representation of film thickness. 


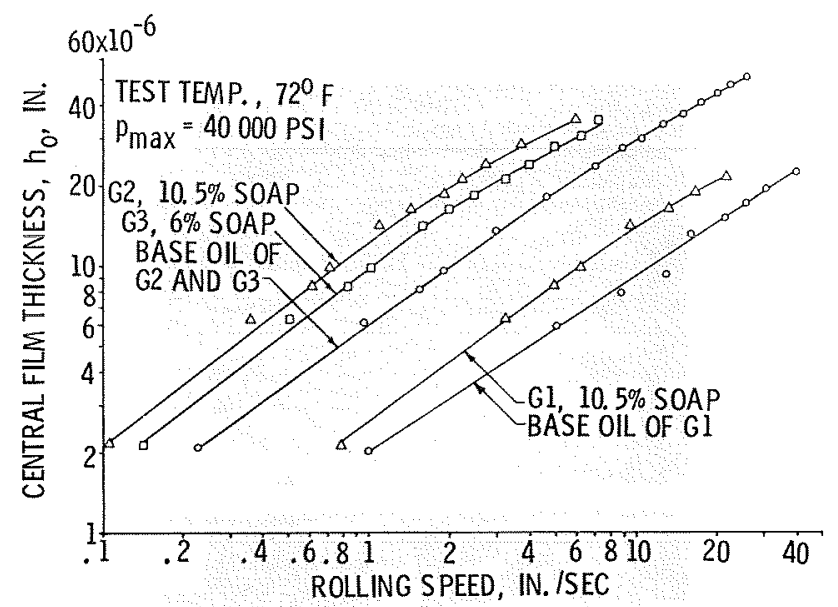

Figure 20, - Film thickness versus speed for three greases and their base oils.
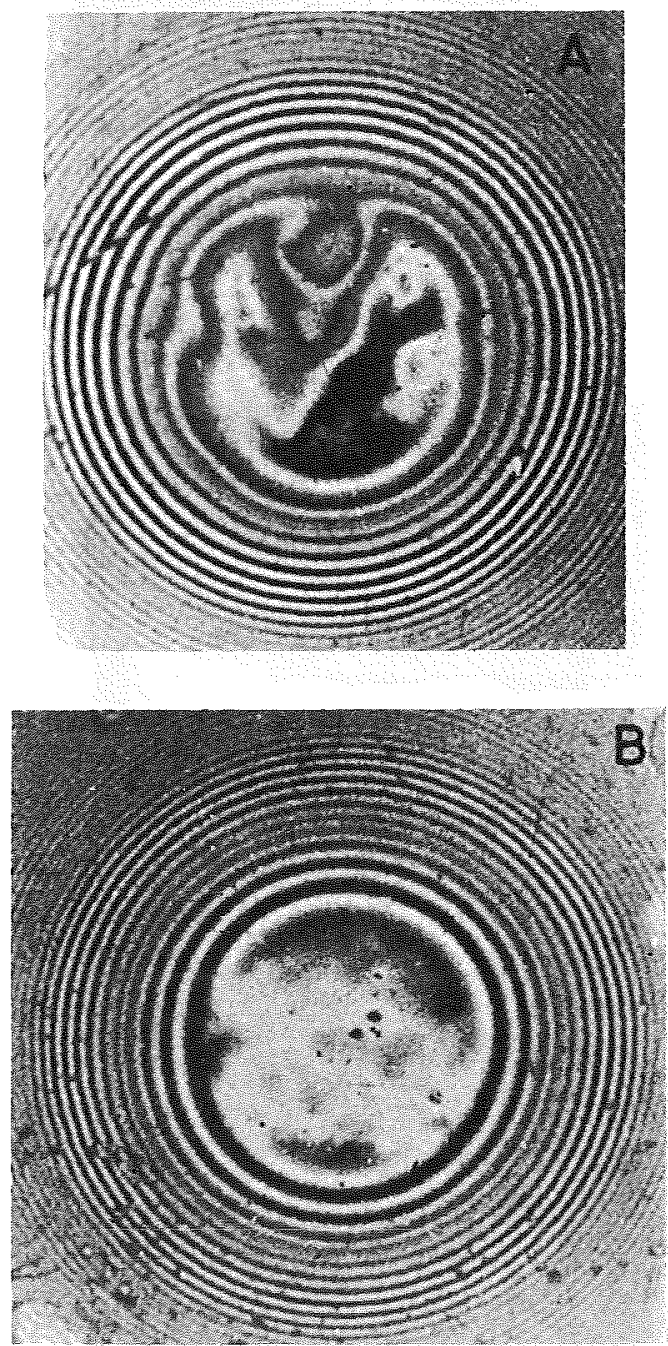

Figure 21. - Grease films under static conditions: (a) obtained after rolling in fresh grease, (b) obtained after rolling several times over the same track. 

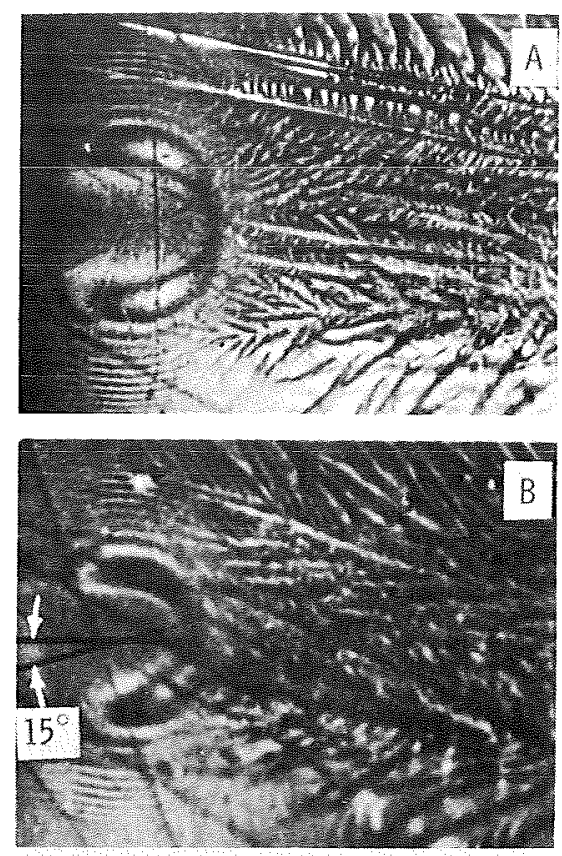

Figure 22, - Observation of ball spin: (a) no spin at cage speed of $263 \mathrm{rpm}$, (b) ball spins at cage speed of $300 \mathrm{rpm}$.
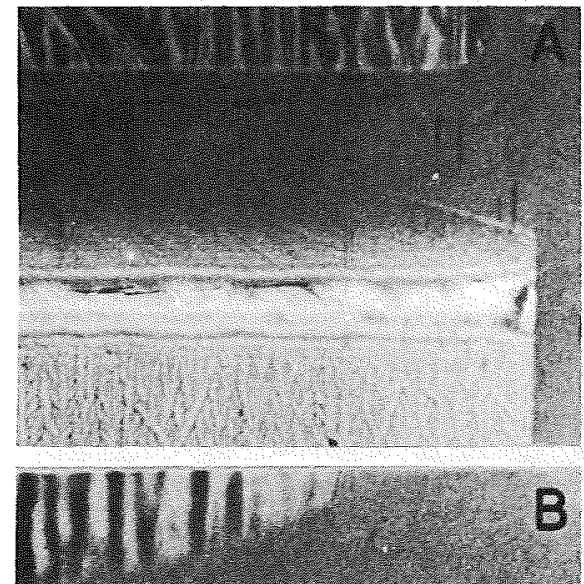

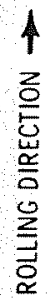

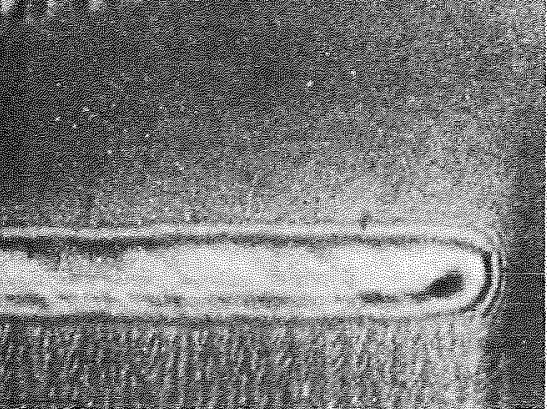

Figure 23. - Edge effects in line contact: (a) unblended roller end, (b) blended roller end. 